\title{
Government Intelligence, Efficacy and Adaptability in Changing Environments
}

\author{
Tuomo Rautakivi \\ Faculty of Public Administration, Burapha University \\ (rautakivi@buu.ac.th)
}

\begin{abstract}
:
Societies change through external pressures from a changing environment, or immanently from the internal cultural dynamic that naturally occurs within social agencies. As a result these political, security, social, economic and other changes are needed that present challenges to public administration. Consequently, public administration must adapt and identify the development of new policies and functions. Of critical importance to the state are the preeminent public institutions that are part of the development process. The outcomes are the result of both public policy and government efficacy. Organizational adaptability involves the anticipation of the future, where adaptation is an internal process that is prompted by environmental change and self-production. The capacity of an agency to adapt is affected by efficacy which conditions it to be effective and efficient. Efficacy is therefore a precondition for successful adaptability and the ability to adapt is a consequence of efficacy. Inefficacy, through its bounding effect on an agency's intelligences, sets limits to its capability of achieving high levels of performance in organizations. Efficacy can be examined in terms of a cybernetic model of a cognitive social agency, allowing distinctions to be made between public policy objectives and the resulting outputs, this thus enabling proposed measurement of efficacy.
\end{abstract}

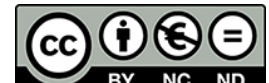

\section{Introduction}

In this paper our interest lies in social human agency:an adaptive human activity group (like an organisation or nation state) that has choice, internal dynamics, an autonomous capacity to self-manage through political governance, administrative structures and some degree of intelligence, delivering policy that drives behaviour, and having a recognition that it has an external environment to which it can respond. Environmental changes challenge public policy and administration systems. As Huntington (1967) tells us, the primary problem of politics is the lag in the development of political institutions behind external change. That may lead to a gap between demand and supply and, in turn, reveal to governments the critical importance of the state and the preeminent public institutions in the development process $^{1}$ (Amsden, 1988). Public policy embraces objective participants in its formulation and employs its resources for achieving objectives of policy, to compound managerial action, and in policies and administration in the public sector (Lane, 2000). The challenge of the countries is in its concepts and how the application will integrate with all functions in settings policy goals, implementing and assigned rules for monitoring, and regulating and controlling these roles. Efficacy of Governance (Yolles\&Fink, 2011) plays an integral role in achieving these goals and created dynamic stability.

The outcomes are the result of public policy and government efficacy.

Public policy is an output of the political system (Jreisat, 2002) and Public policy reflects regimes values to commitment of relevant institutions and views of the whole society. Bureaucracy is under political control and its implementation and the monitoring of this is the function of its bureaucracy. Political pressure on the bureaucracy can emanate from different and even competing groups of principals (Waterman, Rouse \&Wright, 1998). Public policy embraces objective participants in its formulation and employs its resources for achieving objectives of policy, to compound managerial action, and in policies and administration in the public sector (Lane, 2000). The challenge of public administration is dealing

1 This study focuses mainly on developing countries in South East Asia. 
with these concepts and knowing how their application will integrate with all functions in setting policy goals, implementing and assigning rules for monitoring, and regulating and controlling these roles. The efficacy of governance (Yolles\&Fink, 2011) plays an integral role in achieving these goals and creating dynamic stability.

Both large scale and small scale systems need to maintain their stability if they are to survive. Dynamic stability is concerned with the achievement of goals in purposeful systems, and couples intention with achievement (Berlinski, 1975).

Bureaucracies in complex political systems are not usually efficient (Gajduschek, 2003), and their adaptability is often limited to the capacity of the political system to introduce change within the bureaucracy (Yolles\& Fink, 2011). Efficacy conditions the capacity of the system to be effective and efficient, so efficacy influences an agency's capacity for adaptability. It can be said, then, that the ability to adapt is a consequence of efficacy. We have noted that agency refers to autonomous social human groups. These can be modeled as systems that are"self-organizing, proactive, self-regulating, and selfreflecting, and they are participative in creating their own behaviour and contributors to their life circumstanceslinked to information processes with both the self-efficacy (the belief one has about one's efficacy) of an individual agent and the 'collective efficacy' (the collective belief about its efficacy)of a collective agent. Efficacy is conditioned by emotive imperatives (deriving from emotions and feelings) that can be controlled (Adeyemo, 2007) by emotional intelligence (Salovey\& Mayer, 1990). Efficacy influences an agent's capabilities to produce designated levels of performance that exercise influence over events that affect life" (Yolles\& Fink, 2013)

Yolles (2006), citing Piaget, (1950), explain that an agency's intelligences determines its efficacy. Here, two core intelligences are figurative (a form of autogenesis: Schwarz, 1997) which provides core relational explanations of reality, and operative intelligence (a form of autopoiesis: Schwarz, 1997; Maturana and Varela, 1987) which provides for a capacity to evidence its figurative base. Figurative base means self-creational base and abstraction, while operative base means self-producing and practical implementation.

"A system is adaptive when it experiences a qualitative change in form at some level of consideration, and this is accompanied by a change in the patterns of its behavior" (Yolles, 1999:158). Yolles also notes that adaptability involves anticipation of the future. Adaptation is an internal agency process that is prompted by environmental change and self-production. He continues by saying that purposeful adaptive organizations also have the ability to apply knowledge in any situation of interest, and to continually learn from new experiences in order to be able to respond to similar situations in the future and that he calls dynamic stability (Yolles, 2006: 237,543). Dynamic stability is concerned with the achievement of goals in purposeful systems, and couples intention with achievement (Berlinski, 1975). Beauchamp (2002) refers to the achievement of immediate and longer term goals is considered a necessary condition for progressive development.

\section{Pressure of Change and Challenges for Public Administration}

External changes are whatever political, economic or social forces that pressure administration for changes. In South East Asian countries, both national development and the development of ASEAN pressure public administration. In developing countries like some of those in South East Asia, bureaucratic power and inefficiency is the result of lack of political development (Riggs, 2001).Bureaucracy constitutes a ruling class with its own interests and thus bureaucratic dominance has an adverse effect on the future of political development (Riggs, 2001). Gajduschek (2003) noted that inefficacy means the lack of adaptive capabilities.

Bureaucracy is a powerful institution in society and it can increase or decrease the state's capacity for effective performance (Jreisat, 2002).In developing countries, changes are linked to the attitudes of 
political leaders and how far political elites support change (Riggis,2001). This begs the question of what to change in public administration and how much change is allowed as well as how to deal with a changing environment.

Public administration development is related to institutional development inlay society. Whenever philosophical, ideological, economic or technological changes occur, public administration is challenged to develop its own functions and future anticipation. Traditional presumptions assume that bureaucratic systems are rigid and unable to change or be innovative and effectively respond to changes, even though there is evidence for successful development when environments change, like Singapore's administration's development history.

Traditionally, bureaucracy conforms to a prevailing situation and seeks routinization and standardization of procedure which causes inflexibility and avoids development. This point of view, together with the attitudes of the prevailing elites, challenges public administration and its capacity to develop when environments change.

Apprehension of this reveals that implementation of changes are most effective when institutions have the capacity to learn from the past and anticipate the future to adapt advancements in new knowledge.

\section{Adaptability and Public Policy}

In order to understand the nature of adaptability, a set of factors that constitute adaptability and adaptation must be considered. Adaptability is a function of intelligence, enabling a self-organizing body to reposition itself for a new future. The impetus for change comes from a changing external environment, so adaptable actors must be responsive to change. In short, adaptability is an internal process influenced by external forces. For adaptability to be purposeful, it must first be expressed in the form of a cognitive "virtual image" that has within it optional variety (as part of the figurative base). This variety can be enhanced through the creation of new knowledge and implementation appropriate to action (as part of the operative base).

Like any bureaucracies, those in complex political systems are not usually efficient (Gajduschek, 2003) and their adaptability is often limited to the capacity of the political system to introduce change within the bureaucracy (Yolles\& Fink, 2011)."The primary function of national governments also change as nations move from one stage to another, and at each stage of the national government, if it is to qualify as development, it must fill a new function as well as consolidate the gains of previous developments" (Organski, 1965: 7). Huntington called this 'the adaptability of a government'. Functional adaptability, not functional specificity, is the true measure of a highly developed organization (Huntington, 1968). Pye $(1966$, pp. 38,51$)$ notes that the development and modernization are rooted in the need to create more effective, more adaptive, more complex and more rational organizations. Development is the capacity of people to establish and maintain large and complex, yet flexible organizational forms. Efficacy of the Government related capacity to create desired result to develop appropriate institutions as public policy, following environmental changes and modernization. Institutionalization is the process by which organizations and procedures acquire value and stability according to Parsons and Robert (1955). The level of institutionalization of any political system can be defined by its adaptability, complexity, autonomy and coherence (Parson \& Robert, 1955). Institutionalization makes organizations more than just an instrument to achieve certain purposes (Selznick, 1957).Recognition that implementation of societal change is most effective when administered by institutions that have the capacity to learn from and adapt to advancements in human knowledge (Pye, 1962). When an organization confronts a changing environment, it must, if it is to survive, weaken its commitment to its original function and consider the changing environment (Rautakivi, 2012: 40).

"A system is adaptive when it experiences a qualitative change in form at some level of consideration, and this is accompanied by a change in the patterns of its behavior" (Yolles, 
1999:504). Yolles(2006:42) also notes that adaptability involves anticipation of the future, where anticipation is expectation and prediction with experience from the past. Mackiewicz (2006) mentions that anticipation may play a surprisingly important role in how fresh the memory of a tough experience remains. Adaptation is an internal process that is prompted by environmental change and self production. Yolles $(206,237)$ continues that "Purposeful adaptive organizations also have the ability to apply knowledge in any situation of interest and to continually learn from new experiences in order to be able to respond to similar situations in the future".

\section{Organizational Efficacy}

There are clear distinctions between strong government and government efficacy. Most studies emphasize strong government or a strong state when describing a government's success, in particular, in relation to newly-industrialized Asian countries, as illustrated by Lim (2006) in his book on comparative politics. The problem with this term is that a strong government is defined as "an effective and pragmatic government", and a strong government does not necessarily mean strong output and outcomes in terms of economic development or social development. A Government can be strong, without desired output and outcomes, and it can be unable to adapt new functions or create dynamic stability (Rautakivi,2012).

Governments involve actions of publicly vested authorities (Isham, Kaufman, \& Pritchet, 1997). A Government's social and economic outcomes depend on governance, the government's actions and their capacity to create dynamic stability and adaptation and adjust their policies when environments change, hence Government efficacy regards implementing public policy, evaluating, managing and controlling changes, and the capability to adapt new functions in changed environments. This can be referred to as an agency's capability to achieve its political goals. The outcomes can be positive or negative depending on the efficacy of the government.

Efficacy provides capabilities for an organization to produce designated levels of organizational performance that exercise influence over events that affect life (Bandura, 1991). Efficacy is the capacity of the system to be effective and efficient, so efficacy influences the capacity for adaptability. The ability to adapt is a consequence of efficacy. Following Huntington (1968), the more adaptable an organization or procedure is, the more highly institutionalized it is, and this in turn depends on, and varies with, time and environmental changes, which are a function of environmental challenges and age.

Efficacy can be related to the capability of an agency to achieve goals with appropriate actions seen as performance, while perceived efficacy can be set within the context of beliefs and expectations about such capability. In respect of the latter, Bandura (2004: 171) defined efficacy (with respect to belief) as the shape of people's outcome expectation-whether they expect their efforts to produce favorable outcomes or adverse ones. Similarly, self-efficacy beliefs determine how an agency feels, thinks, motivates itself and behaves, so self-efficacy is the belief that one (agency) has their capability, which may not mean efficacy or favorable outcomes. The beliefs produce diverse effects through the major processes of cognition, motivation, effectiveness and selection of appropriate policies (Yolles\& Fink, 2011). Bandura (1986) defines collective efficacy of the agency as the shared belief that can, as a whole, attain goals and accomplish its desired tasks. Yolles and Fink (2011) also mention that it is also feelings/emotions which occur in the individual, and these feelings/emotions may also develop a normative dimensionality in a collective. In both cases, emotions can also affect agency performance. The efficacy of an agency will also influence its ability to communicate, goal-set, and persevere during adversity. Penpanich (2011) defines governance efficacy as the abilities of governments to produce designated levels of official performance that exercise influence over political activities such as public policy implementation. It is the power of governments to reform the features of politics in their country through positive and appropriate policy making and equitable resource allocation 
Yolles and Fink (2010) define the efficacy in the organization level as efficacy is the capacity for producing a desired result or effect. The efficacy of agencies relates to "the soundness of their thoughts and actions, and the meaning of their pursuits, and they make corrective adjustments if necessary" (Bandura (2006: 165). Efficacy is conditioned by emotive imperatives (deriving from emotions and feelings) that can be controlled (Adeyemo, 2007) by emotional intelligence (Salovey\& Mayer, 1990). Efficacy therefore influences an agent's capabilities to produce designated levels of performance that exercise influence over events that affect life. Bandura (2006) also refers to empirical research which shows that perceived collective efficacy accounts for distinctions in the quality of group functioning in diverse social systems.

Efficacy is influenced by the available cognitive resources capable of collecting, recognizing, evaluating and processing information, and by the conforming or conflicting interests of agents within the organization that encorporate conflicting or identical goals and capability to create dynamic stability (Yolles\& Fink, 2010, p. 3). This notion of efficacy may be expressed in terms of dynamic stability which means public administration's capability to adopt new functions such as the capacity to absorb environmental changes without external or internal conflicts.

\section{Intelligence and Efficacy}

In this paper we centre the concept of intelligence on that posited by Piaget. Piaget $(1956,1973,1976)$ and Yolles (2006, 2011, 2013). Piaget (cited in Elkind, 1976: 56) explains that intelligence may be seen as an interactive function that connects two distinct entities, cognitive and operative skills, hence creating a connective orientation between the two which through that interaction, intelligence organizes the world by organizing itself. So, intelligence is something that creates an internal connective orientation within an agency towards its external environment. This orientation and ability is connected to the capacity of an agency to adapt since "Intelligence is an adaptation thus to suppose that it [adaptation and adaptability] is essentially an organization to be viable and that its function is to structure the universe just as the organism structures its immediate environment" (Piaget, 1963, pp. 3-4, cited in Plucker, 2012; Yolles, 1999). Intelligence also involves the process of assimilation "to the extent that it incorporates all the given data of experience from paste within its anticipation of future and changes in environment. Assimilation is part of the adaptation process by which an agency takes in new experiences and incorporates them into its existing knowledge and information.

If the function of intelligence is to connect information between cognitive and operative skills through the creation of a connective orientation, then this says nothing about the capability of manifesting that information. This is rather the function of efficacy which is an indication of the capability of the intelligence to manifest information between systems of agency (Yolles, 2013). Efficacy therefore influences an agent's capabilities to produce designated levels of performance that exercise influence over events that affect life (Yolles\& Fink 2010) so efficacy determines the capability through which intelligence operates.

Efficacy needs different traits of intelligence and efficacy is the result of control on emotive weightings that are applied to the manifestation of distinct types of information by the intelligences, often summed up through the word capability (Yolles, Fink, Dauber, 2010:14). There are several kinds of intelligences which are commonly used in the literature such as cultural, social, emotional, cognitive, figurative and operative intelligences (Sagiv and Schwartz, 2007). This study concentrates on figurative and operative intelligences which constitute efficacy as the precondition for adaptability and adaptation.

Intelligence is the ability to understand and realize one's knowledge of environment to construct new knowledge and convert information about its experiences and past, and thus pursue its goals. 
Intelligences enable the consideration of interests and influences of the external environment, an agency's own goals, the goals of others, and facilitation of the development of ideas about the possible reactions of others in relation to the action taken by the agency (Fink \&Yolles 2012: 2). So intelligence is the capacity of an agent to discover its own knowledge and information about its environment, to construct new knowledge converted from information and experiences from the past, and pursue its goals effectively and efficiently; all of which are terms associated with the concept of efficacy.

Piaget and Inhelder (1973) described figurative intelligence as a more-or-less static part of intelligence, involving all means of representation which are retained and that intervene between transformations. That is, it involves perception, imitation, mental imagery, drawing, and language, while operative intelligence is the active part of intelligence. It involves all actions, overt or covert, undertaken in order to follow, recover, or anticipate the transformations of the objects or persons of interest.

An agency is efficacious through its figurative and operative intelligences. As illustrated in Figure 1 that is intended to represent the adaptive agency, figurative intelligence is represented by Yolles as a form of autogenesis and provides relational explanations of reality (Schwarz, 1997). Figurative images like mental models and abstractions have been solidified from the strategic part of an agency that is referred to as its normative personality (Yolles \& Fink,2011). Figurative intelligence enables the creation of appropriate and suitable policy instruments that are consistent with its ideology and ethics to deal with what it sees around it, so figurative intelligence is a set of figurative images (including mental models and abstractions).

Operative intelligence is, for Yolles, a form of autopoiesis (Maturana \& Varela, 1987) and provides for its capacity through evidence from its figurative base which refers to the capacity of an agency to maintain beliefs, values, and knowledge. Attitudes derive from values and are described as a set of values that are directed towards some object of attention and hence have an operative function. So operative intelligence is the efficacy of personality structures that facilitate and condition behaviors from which the term 'performance' arises (Yolles\& Fink, 2011). Operative intelligence refers to the capacity for beliefs, values, attitudes and knowledge to be assembled in an operative function. Operative intelligences enable the implementation of the policy provisions through its bureaucracy. Policy does appear there after the decision making process. The policy is created in the strategic system and delivered in the agency operative system through agency operative intelligence, and where the bureaucracy locates. For Yolles and Fink (2011), the capacity of a social entity to function coherently is determined by its collective efficacy. There is a relationship between adaptability, efficacy and intelligences, so it can be said that for decision making to be effective, governments or organizations must know and identify what should be done and be aware of their goals on a broad level (figurative intelligence) which is exactly what must be done in order for governments or organizations to learn and adapt (Yolles, 2006, p. 240). Yolles continues by saying that the government or organization must know or identify what must be done in order to achieve the desired results and output and implement the policies, which is what he calls efficient (operative intelligence). So operative intelligence has the efficacious capacity of a normative agent ${ }^{2}$ to create a cycle of activity that manifests figurative projections as operative objects.

2 Normative agency is agency, s capacity to choose and to pursue our conception of a worthwhile life (Griffin, 2008: 45) Normative agents must satisfy the regular notions associated with artificial agents and possess the capability torepresent norms in a format that allows them to be reasoned over and modified during the lifetime of the agent, including: 1) knowledge representation, 2) Learning, 3) morality and law (Hollander and Wu, 2011).Normative agent architectures are largely based on belief, desire, and intention (Neuman, 2010) 


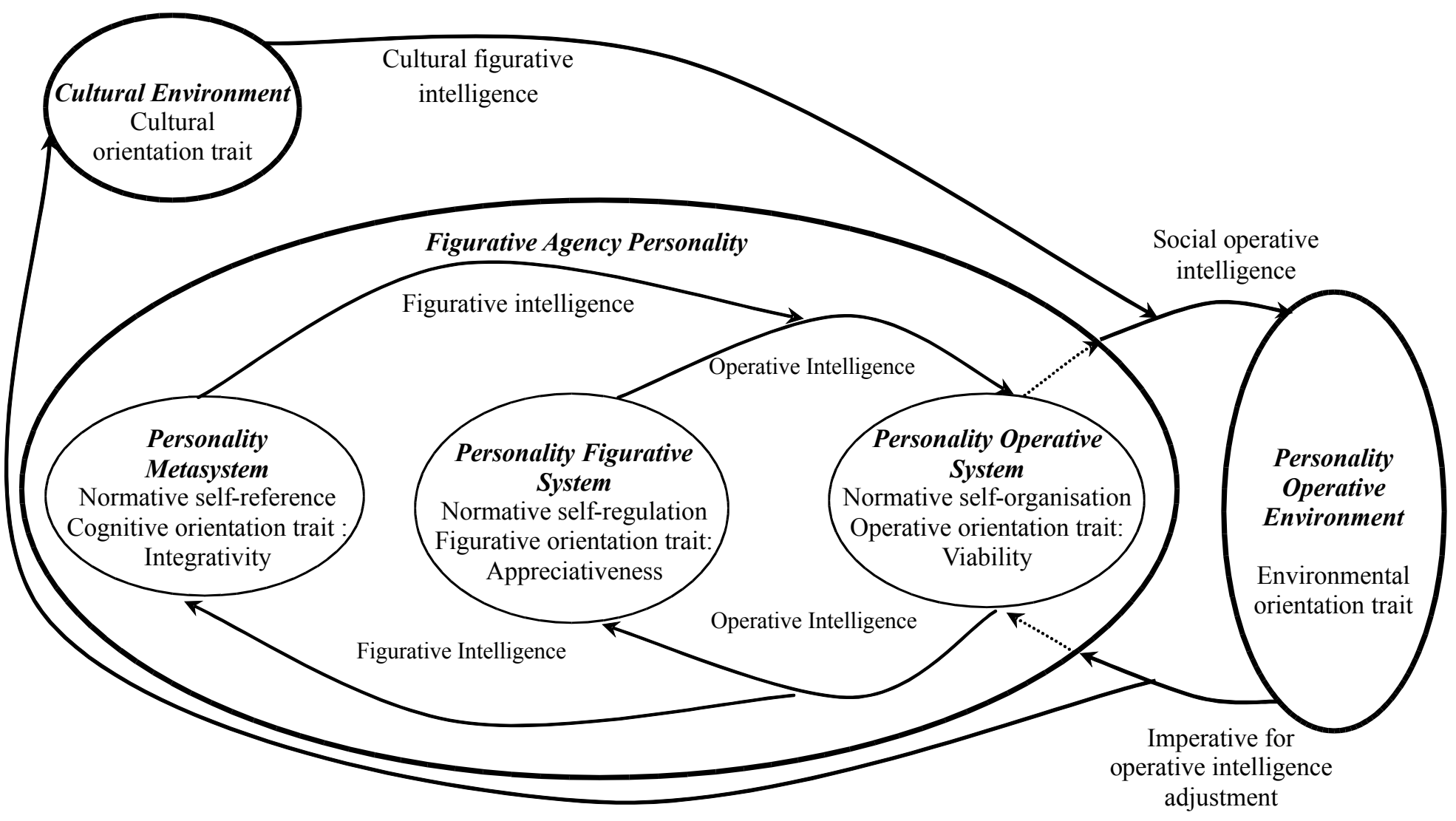

Figure 1: A Model of the Agency and the Nature of its Intelligences. Source: Yolles\& Fink (2012)

There are also cultural intelligences which refer to learned social behaviors and how humans make moral (normative), social (structural) and personal (behavioral) choices (Apter, 19656, 10). Cultural intelligences provide standards for perceiving, believing, evaluating and acting (Thomas, 1993:12).

\section{Measuring Efficacy:}

Measuring efficacy within a process of development should focus on the impact of how, and how well, government policies aggregate economic outcomes or social outcomes, means such as Most Similar System Design (MSSD), where the differences in the dependent variables may give comparable information of efficacy. Isham et al. (1997), mention that nearly all data concerning government actions concern public resources spent on inputs, not comparable outcomes. We can learn very little from the input or output data alone and certainly nothing about government efficacy (Lant, 1996).

Efficacy is the capability of an agency to create performance. While Bandura's original concept of efficacy related to operative intelligence, it can also be related to other forms of intelligence. In Figure 1 they are deemed to operate through the intelligences in the following way (i.e., an agency's normative personality) within and beyond the within the strategic agency (Yolles \& Finck 2012)

国 Efficacy is related to figurative intelligence in that given that there is cognitive information that has formed attitudes, emotions, and goal imperatives and self-reference; the manifestation of this cognitive information to the operative couple into the figurative system may not be fully reflective of the needs of an agency, impacting on the agency's capacity to form appreciative 
schemas like goals. Inefficacious manifestations of this cognitive information may result in inappropriate figurative models that impact directly on operative decision making. Efficacy measures may be made by comparing cognitive information with the figurative schemas that arise.

国 Efficacy is related to operative intelligence in that its figurative schemas are manifested into the operative system to enable decision making about policy. So appreciative information that has structured cognitive information into schemata to generate goals, decision imperative and feelings (all influenced by ideology and ethics) are manifested into operative decision making structures. Poor operative intelligence there is often seen in terms of inefficacious behaviour. Measures of efficacy may arise by comparing figurative schemas with decision outcomes under known contexts.

困 Efficacy is related to agency operative intelligence (a form of economic intelligence), as decisions are manifested into a social context through the creation of policy. Efficacy can be measured by comparing decisions with the policies that develop within the agency operative system.

[. Efficacy is related to behavioural intelligence through the implementation of policy within a social environment. This is to a large extent the function of bureaucracy, which therefore may be seen to have degrees of efficacy that make it behavioural intelligent or not.

[ Efficacy is related to cultural intelligence as attributes of knowledge; emotional imperatives and identity are manifested into the strategic economic agency as information. Efficacy can be measured by comparing cultural attributes with the cognitive system information that has been manifested, e.g., through the formation of goal imperatives or attitudes.

Efficacy measures can also be made by relating these policies to other attributes of the strategic agency, like goals or cognitive information and policy or policy implementation. The measurement of efficacy needs criteria to be established to enable it to be applied to the analysis of government outcomes.

\section{The Government Efficacy Criteria for Measuring Government Efficacy (the Abilities of a Government to Produce Designated Levels of Operative Performance)}

The criteria for Government efficacy are the factors that enable the analysis of efficacy within a government with respect to its socio-economic development and environmental changes.

According to Bandura's $(1986,1997)$ self-efficacy theory, it provides a useful framework for the study of behavior within government efficacy. Self-efficacy represents the level of people's confidence that they can successfully produce favorable or adverse outcomes. These efficacy beliefs are thought to have important motivational implications in that they impact an individual's choice of activity, effort, and persistence. Given that an individual has the requisite skills, self-efficacy is hypothesized to positively influence performance (Bandura, 1986). His main idea concerning an agency of efficacy states that: "People are not solely agents of action. They are also self-examiners of their own functions. Through functional self-awareness, they reflect on their personal efficacy.

Bandura proposed that Collective Efficacy as an Extension of Self-Efficacy. Collective efficacy involves the individuals' perceptions regarding the group's performance capabilities. Collective efficacy beliefs have substantial implications for group effort, persistence, and performance, especially for tasks requiring interaction among group members for success (Bandura, 1990).

Many of the challenges of life are group problems requiring collective efforts to produce significant change. The strength of groups, organizations, and even nations lies partly in people's sense of collective efficacy that they can solve the problems they face and improve their lives through a unified effort. The exercise of individual and collective agency is contributing increasingly, in virtually every sphere of life, to human Development, Adaptation, and Change (Bandura, 2004) 
While Bandura highlighted the importance of efficacy to the agency, in his later work he centered on perceived efficacy. Yolles and Fink (2010) is interested in efficacy in an organization, which they see as relating to the capacity for producing a desired result or effect, and hence can be represented in terms of the dynamic stability of an agency. Efficacy is influenced by the available cognitive resources (capabilities to collect, recognize, evaluate and process information) and by conforming or conflicting interests of agents within the organization conflicting or identical goals (Yolles\& Fink, 2010, p. 3).

This paper has drawn up the requisite criteria from factors, based on the ideas of, which enable for an effective analysis of the government efficacy (based of four Asian Newly Industrialized Countries Asian NICs) with respect to the development and modernization process as follows: (1) policy and a reflection of the need of good governance; (2) Means of implementing policy; (3) Adaptability (involves the consideration of environment).

The criteria for government efficacy pertaining to the development and modernization process, is given with a brief description of the meaning shown in Table 1.

Table 1

The Government Efficacy Criteria for Measuring Government Efficacy (the Abilitiesof a Government to Produce Designated Levels of Operative Performance)

\begin{tabular}{ll}
\hline Criteria & Brief Meanings \\
\hline policy and a reflection of the need & $\begin{array}{l}\text { How did the public policies respond to } \\
\text { the public needs and is it amenable for } \\
\text { demand? }\end{array}$ \\
Means of implementing policy & $\begin{array}{l}\text { How did the government implement the } \\
\text { economic policy that facilitated FDI? } \\
\text { How did the government implement the } \\
\text { economic policy that facilitated economic } \\
\text { modernization? }\end{array}$ \\
& $\begin{array}{l}\text { How did the government implement the } \\
\text { social policy that facilitated social } \\
\text { modernization ? }\end{array}$ \\
& $\begin{array}{l}\text { How did the government adapt its } \\
\text { policies when the context/environment } \\
\text { changed? }\end{array}$ \\
\hline $\begin{array}{l}\text { Adaptability (involves } \\
\text { consideration of the environment) }\end{array}$ &
\end{tabular}

Source: Rautakivi, 2012

Table1 indicates to what extent the political agencies' capabilities are in terms of achieving their political goals and outcomes. The result off outcomes may explain the efficacy of government and public policy. The meaning of a government's political pursuit for political outcomes is grounded in the idea that social and economic development creates prosperity for all layers in a society. This is in regards to a government's capability to produce favorable outcomes and its capacity to create collective goods. A government's good governance comes from responding to public needs. Efficacy therefore influences agents' capabilities to produce designated levels of performance that exercise influence over events that affect life (Yolles, Fink, \& Dauber, 2011). A government must have the capabilities to create better policies that satisfy the demands of the people after context or environmental changes. 


\section{Conclusion}

Adaptability is not a simple process responding to changing environments: it is a complex system which requires different kinds of organizational skills and intelligences. Adaptability is an ambiguous and diverse process where different kinds or traits affect and constitute capacity for adaptation. Efficacy is the capacity of the system to be effective and efficient, so efficacy influences the capacity for adaptability. The ability to adapt is a consequence of efficacy. Intelligence is the ability to understand and realize one's knowledge of the environment to construct new knowledge and convert information about experiences and the past, and pursues goals and creates internal changes driven by external pressures from a changing environment.

\section{References:}

Adeyemo, D.A., (2007),Moderating Influence of Emotional Intelligence on the Link Between Academic Self-efficacy and Achievement of University Students, Psychology Developing Societies, 19(2) 199213.

Amsden, A. H. (1988). Taiwan's economic history: A case of teatime and a challenge to dependency theory. In R. H. Bates (Ed.), Toward a political economy of development: A rational choice perspective (pp. 142-175.) Berkeley, CA: University of California Press.

Bandura, A. 1991, Self-Regulation of Motivation Through Anticipatory and Self-Reactive Mechanisms, in Dienstbier, R.A., (Ed.), Perspectives on motivation: Nebraska symposium on motivation (Vol. 38, pp. 69-164), University of Nebraska Press, Lincoln.

Bandura, A. (2004). Cultivate self-efficacy for personal and organizational effectiveness. Malden, MA: Blackwell.

Bandura, A., 2006, Toward a Psychology of Human Agency, Association for Psychological Science, 1(2)164-180

Beauchamp, A. E. (2002). System approach and managing diversity in complex systems: Towards dynamic stability. New York: Red Hoo.

Berlinski, D. (1975). Mathematical models of the world. Synthese, 31(1), 211-227.

Elkind, D. (1976). Child Development and Education, www.scribd.com/doc/5079000/childdevelkind, accessed May 2013

Griffin, James, 2008, On Human Rights, Oxford University Press,

Gajduschek, G. (2003). Administration \& Society, Vol. 34 No. 6, January 2003, 700-723 DOI: 10.1177/0095399702239171 (C) 2003 Sage Publications http://cc.scu.edu.cn/G2S/eWebEditor/uploadfile/20121216002248421.pdf

Hollander,Christopher D., Wu, Annie S., (2011) The Current State of Normative Agent-Based Systems, Journal of Artificial Societies and Socialsimulation http://jasss.soc.surrey.ac.uk/14/2/6.html

Huntington, S. P. (1968). No easy choice: Political participation in developing countries. Cambridge, MA: Harvard University Press.

Isham, J., Kaufmann, D., \& Pritchett, L. H. (1997).Civil liberties, democracy, and the performance of government projects. The World Bank Economic Review, 11(2), 219-242.

Jreisat, J. E. (2002). Comparative public administration and policy.Boulder, CO: Westview Press.

Lane, J. E. (2000). The public sector, concepts, models and approaches. London: SAGE.

Lant, P. H. (1996). Mind your P's and Q's:The cost of public investment is not the value of public capital (Policy Research Working Paper 1660). Washington, DC: The World Bank, Policy Research Department, Poverty and Human Resources Division.

Mackiewicz Kristen University of Wisconsin-Madison (2006, September 7). Anticipation Plays A Powerful Role In Human Memory, Brain Study Finds. ScienceDaily

Maturana, H. R., \& Varela, F. J. (1987).The tree of knowledge. London: Shambhala. 
Meier, Kenneth J., and George A. Krause.2003 (2005). "The Scientific Study of Bureaucracy: An Overview." A review essay in the co-edited book volume Politics, Policy, and Organizations: Frontiers in the Scientific Study of Public Bureaucracy. George A. Krause and Kenneth J. Meier, eds. Ann Arbor, MI: University of Michigan Press.

Organski, A. F. K. (1965). Stages of political development. New York: Alfred A. A. Knopf.

Parsons, T., \& Robert, F. B. (1955).Collaboration with. In P. E Slater M. Zeldich, \& J. Olds (Eds.), Family socialization and interaction process (pp. 120-147). London: Routledge and Kegan Paul.

Piaget, J., \& Inhelder, B. (1973).Memory and intelligence. London: Routledge and Kegan Paul

Pye, L. (1962). Politics, personality and nation building: Burma's search for identity. New Haven, CO: Yale University Press.

Pye, L. (1966). Aspects of political development. Boston: Little Brown

Rautakivi,T. (2012). The Role and Effects of Efficacy in Socio-Economic Development and Foreign Direct Investment: A Comparative Study of South Korea and Singapore. Bangkok: Ramkamhaeng University

Riggs, Fred W. (2001). "Bureaucratic Links Between Administration and Politics in Handbook of Comparative and Development Adminitration, $2^{\text {nd }}$ ed. Ed. A. Farazmand. New York: Marcel De Dekker.

Sagiv, L., and S.H. Schwartz, 2007 'Cultural values in organisations: insights for Europe'. European J. International Management, Vol. 1, No. 3, pp.176-190.

Salovey, P., Mayer, J.D., 1990, Emotional Intelligence, Report for the NTH Biomedical Research Support Grant S07 RR07015, NIH grant CA42101, NCHS Contract 200-88-7001, Haywood Publishing Co., Inc.

Selznick, P. (1957). Leadership in administration. New York: Harper \& Row.

Schwarz, E. (1997). Towards a holistic cybernetics: From science through epistemology to being. Cybernetics and Human Knowing,

Thomas, J. (1993). Doing Critical Ethnography.Qualitative Research Methods Series, no. 26. Newbury Park Calif.: Sage

Waterman, R. W., A. Rouse, and R. Wright (1998), 'The Venues of Influence: A New

Theory of Political Control of the Bureaucracy', Journal of Public Administration Research and Theory,

Williamson, O.E., (1999), Public and Private Bureaucracies: A Transaction Cost Economics Perspective, Journal of Law, Economics \& Organisation,15(1)306-324, www.edegan.com/pdfs/Williamson $\% 20 \% 281999 \% 29 \% 20-\% 20$ Public\%20and\%20Private\%20Bureaucracies.pdf

Yolles, M. I. (2006). Managing the complex: Organization as complex systems: An introduction to knowledge cybernetics. Greenwich, England: Information Age.

Yolles, M.. I,. Fink, G. (2011). Understanding Organisational Intelligences as Constituting Elements of Normative Personality. Paper presented at IACCM 2011, Ruse Bulgaria Revision, October 2011, http://www.wu.ac.at/iaccm/2011

Yolles, M.I., Fink, G. (2011). Agencies, Normative Personalities, and the Viable Systems Model, Journal Organisational Transformation and Social Change, 8(1)83-116

Yolles, M.I., Fink, G. (2013). Exploring the Common Roots of Culture, Politics and Economics, Business Systems Review, 2(2) in process. 
